\title{
End-of-Life Practices in France under the Claeys-Leonetti Law: Report of Three Cases in the Oncology Unit
}

\author{
Alexandre de Nonneville ${ }^{a, b} \quad$ Anthony Marin ${ }^{a, b} \quad$ Theo Chabal ${ }^{a, b}$ \\ Veronique Tuzzolino $^{a}$ Marie Fichaux $^{a}$ Sebastien Salas ${ }^{a, b}$ \\ ${ }^{a}$ Department of Oncology and Palliative Care, Timone Hospital, Marseille, France; \\ ${ }^{b}$ Aix Marseille University, Marseille, France
}

\section{Keywords}

Sedation $\cdot$ End of life $\cdot$ Palliative care $\cdot$ Claeys-Leonetti

\section{Abstract}

On February 2, 2016, the French government enacted the Claeys-Leonetti law introducing the right to deep and continuous sedation and forbade euthanasia for end-of-life patients. This article reports the first descriptions of this kind of intervention at the final stage of life of 3 patients and highlights the need of patient-centered goals and the importance of close collaboration between the patient, family, and medical and paramedical team to achieve a higher quality of final palliative care.

\section{Introduction}

Patients always had, and particularly at the end of their life, rights which are more or less clearly defined by law depending on the country. Many factors of a historical, cultural, social and religious nature may explain these disparities. Three countries in Europe legalized euthanasia since the 1990s [1]. In France, the issue of euthanasia has led to substantial public debate. A first law concerning the rights of patients at the end of life, called 'the Leonetti law' [2] allows since April 2005 the limitation or discontinuation of treatment and sedation 


\section{Case Reports in Oncology}

for a symptom that has remained refractory until death, thereby differentiating such situations from euthanasia. On the February 2, 2016, after the re-examination of questions related to the accompaniment of patients at the end of life and euthanasia by a parliamentary commission, the French Government proclaimed a law called the Claeys-Leonetti law [3]. This law recognizes the wishes expressed by patients and establishes the right to deep and continuous sedation, consisting of sedative and analgesic treatment leading to a profound and continuous change of vigilance to death if the patient is likely to suffer pain, associated with the cessation of all life-sustaining treatments including artificial nutrition and hydration.

Treatment limitation decisions are made daily in our palliative care unit at the Timone University Hospital (Marseille, France) which receives about 150 different patients every year. Since the approval of the law, we have been faced with three sedation requests. Considering this very recent amendment and thus the enhancement of the spectrum of end-oflife care options, we believe it is interesting to share our experience. This article reports the first descriptions of deep and continuous sedation at the request of 3 patients, at the final stage of their lives, in accordance with the Claeys-Leonetti law [3]. Palliative multidisciplinary meetings validated by the French Oncology Coordination Center took place, at which these 3 cases of sedation request were approved.

\section{Case Reports}

\section{Case 1}

Mrs. L. was a 54-year-old patient with a gingival and mandibular cylindroma treated since 1998. She underwent 18 surgeries and several cycles of radiotherapy complicated by mandibular osteoradionecrosis. Morphine was introduced for refractory pain in 2014. In July 2015, the patient had a massive progression and refused conventional chemotherapy. On March 15, 2016, the patient was admitted at her request to our palliative care unit for hemorrhage, pain and respiratory difficulties. She expressed the desire of deep sedation. After a consultation with the oncologist, nurses, husband and patient's daughter regarding our ability to improve her condition, a deep and continued sedation was performed.

\section{Case 2}

Mr. C. was a 70-year-old man followed by our staff since March 2016 for a metastatic clear cell renal carcinoma. He received two cycles of radiotherapy for painful secondary bone lesions despite properly conducted opioid treatment. At the same time, the patient began systemic treatment by pazopanib. In April, pancytopenia revealed a malignant infiltration of the bone marrow. The patient had an extreme malnutrition, and a septicemia occurred in June. Given the failure of the treatment and the patient's clinical condition, pazopanib was stopped. The patient mentioned for the first time his wish to stop all active treatment including antibiotics and blood transfusion despite persistent infection and anemia. His wife and his children were present at the interview with the medical and paramedical team and supported his wish. After a collegial meeting, a deep and continuous sedation was initiated.

\section{Case 3}

Mr. P. was an 84-year-old widower with a personal history of atrial fibrillation and endstage renal disease for which he was on dialysis 3 days per week. He was followed since De- 


\section{Case Reports in Oncology}

cember 2015 by our oncology staff for a rapidly progressive undifferentiated sarcomatoid carcinoma of the gum for which he received three series of radiation therapy with limited tumor response. In May 2016, the patient presented a tumor hemorrhage for which he refused any embolization. In agreement with the oncogeriatrics, we discussed performing chemotherapy with ifosfamide, which he also refused. Pain increased with disease progression and was only relieved by fentanyl. At this moment, the patient wrote advance directives, which prevail over any decision of another person, in accordance with the French law: 'In case of bleeding or respiratory complications, I do not want any invasive investigations. I'm ready to die. I do not want to suffer. If I am admitted into palliative care unit, I would stop dialysis'. The patient was admitted into our palliative care unit on July 5, 2016; he had aphagia and respiratory discomfort due to his tumor. Given the impossibility of improving his condition, we started treatment limitation by stopping dialysis and anticoagulant therapy. On the 8 of July, he requested the medical staff to apply his right to deep and continuous sedation. All members of his family supported his decision. He asked us to start the sedation at 3 p.m., the hour when he was born. After he had seen every member of the family, we were called to perform sedation.

\section{Drugs Used and Outcomes}

For inducing sedation, we used the French Palliative Care Society's recommendations (SFAP) which recommend the administration of $1 \mathrm{mg}$ bolus of midazolam every 3 min until obtaining a Rudkin score of 4 , which is then relayed by a continuous infusion of $50 \%$ of the cumulative doses of the bolus used.

Mrs. L., who had stopped artificial hydration, received 6 boluses of $1 \mathrm{mg}(0.02 \mathrm{mg} / \mathrm{kg})$ of midazolam until Rudkin score 4 was reached, relayed by a continuous infusion of $3 \mathrm{mg} / \mathrm{h}$. For a few days, the patient received oxycodone at $25 \mathrm{mg} / \mathrm{h}$ with a bolus of $30 \mathrm{mg}$. Because of pain and discomfort $4 \mathrm{~h}$ after the beginning of the sedation (score on the Algoplus scale 4/5), we increased midazolam to $6 \mathrm{mg} / \mathrm{h}$ after 1 bolus of $30 \mathrm{mg}$ of oxycodone. We needed to make an adjustment by doubling midazolam at $12 \mathrm{mg} / \mathrm{h}$ once more for discomfort. The patient died 4 days after initiation of sedation.

Because this first patient had needed many boluses before sedation was induced, we used a bolus of $2 \mathrm{mg}$ of midazolam every $3 \mathrm{~min}$ for the second patient, Mr. C., who had stopped antibiotics, artificial alimentation and hydration. We induced the sedation with 5 boluses of $2 \mathrm{mg}(0.03 \mathrm{mg} / \mathrm{kg})$ of midazolam, relayed by a continuous infusion of $5 \mathrm{mg} / \mathrm{hour}$. The patient came out of sedation $12 \mathrm{~h}$ later because he was feeling thirsty. After 6 boluses of $5 \mathrm{mg}$, we increased continuous infusion at $15 \mathrm{mg} / \mathrm{h}$. The patient died $48 \mathrm{~h}$ after initiation of sedation without new awakening or discomfort.

Because the first 2 patients came out of sedation for symptoms of discomfort, we took the decision to administer the entire dose used for induction for Mr. P., who had stopped dialysis and anticoagulant therapy. Four boluses of $2 \mathrm{mg}(0.03 \mathrm{mg} / \mathrm{kg})$ of midazolam were administered every $3 \mathrm{~min}$ to obtain a score equal to 4 on the Rudkin scale, relayed by a continuous infusion of $8 \mathrm{mg} / \mathrm{h}$. A new bolus of $8 \mathrm{mg}$ was performed $2 \mathrm{~h}$ after induction due to respiratory discomfort. The patient died at 7 p.m., $4 \mathrm{~h}$ after initiation of sedation; he was quiet and comfortable. 


\section{Discussion}

The relief of the pain and suffering of terminally ill patients is a human right. The ClaeysLeonetti law created the right to deep and continuous sedation. This right may be exercised by the patient in two situations: when he is a victim of refractory symptoms and when he decides to discontinue vital treatment. The aim of sedation is to prevent the suffering possibly caused by discontinuing treatment for maintaining the patient artificially alive. Palliative sedation is defined as the use of drugs to make patient comfortable and unawareness of the imminent death situation, without intentionally giving death [4]. A major issue of the ClaeysLeonetti law is that the concept of sedation does not have any medical content. The level of palliative sedation varies with the drugs and posology used, and there exists a continuum from simply keeping the patient asleep to inducing an artificial coma.

Sedation occurs at the request of the patient with short-term poor prognosis and not on the physician's assessment. This raises the question of the exact definition of 'short-term poor prognosis', which is not clearly specified by the law. An analysis of international guidelines and position on palliative sedation showed that the concept of short-term prognosis was unclear [5]; especially, it has been demonstrated that treating physicians appear to overestimate the duration of patient's life at the end of the care of cancer patients [6].

Furthermore, there is no conscience clause for the physician to whom the request is made as is the case in France for medical abortion. Palliative sedation can be criticized as being a slow, disguised and socially acceptable form of euthanasia. The main difference between euthanasia, defined as 'the intentional taking of someone's life by another, at his request', and palliative sedation lies in the presence or absence of an intention to hasten death, even if it is questionable when stopping artificial hydration and alimentation. We are also faced with some ambivalence in the patient's expectation regarding time to death under sedation sometimes mistaken with properly so-called euthanasia. After the first application of deep and continuous sedation, a form was developed at the request of the members of the medical team. It includes different items to ensure that the demand remains consistent with the legislative framework, so that the team will not face medical, psychological or social problems, which implement a bias in sedation request.

While the law provides the necessary framework, complementary reflections on palliative care practices are needed. Treatment limitation decisions should be made collegially, and are ideally preceded by early integration of palliative care. Patients should be allowed to die as comfortably and peacefully as possible but should not be euthanized. However, palliative sedation is a complex strategy that requires transparency of the decision-making process based on the medical and ethical values of patient autonomy and caregiver beneficence and nonmaleficence, information of the relatives, and documentation of the entire decisionmaking process in the medical files as safeguards against the inappropriate use of palliative sedation.

\section{Statement of Ethics}

The authors have no ethical conflicts to disclose. 


\section{Disclosure Statement}

The authors have no conflicts of interest to declare.

\section{References}

1 Parpa E, Mystakidou K, Tsilika E, Sakkas P, Patiraki E, Pistevou-Gombaki K, et al: Attitudes of health care professionals, relatives of advanced cancer patients and public towards euthanasia and physician assisted suicide. Health Policy 2010;97:160-165.

2 LOI n ${ }^{\circ}$ 2005-370 du 22 avril 2005 relative aux droits des malades et à la fin de vie. April 23, 2005. https://www.legifrance.gouv.fr/eli/loi/2005/4/22/SANX0407815L/jo/texte.

3 LOI n 2016-87 du 2 février 2016 créant de nouveaux droits en faveur des malades et des personnes en fin de vie. February 2, 2016.

https://www.legifrance.gouv.fr/eli/loi/2016/2/2/AFSX1507642L/jo/texte.

4 Cowan JD, Walsh D: Terminal sedation in palliative medicine - definition and review of the literature. Support Care Cancer 2001;9:403-407.

-5 Gurschick L, Mayer DK, Hanson LC: Palliative sedation: an analysis of international guidelines and position statements. Am J Hosp Palliat Care 2015;32:660-671.

6 Viganò A, Dorgan M, Bruera E, Suarez-Almazor ME: The relative accuracy of the clinical estimation of the duration of life for patients with end of life cancer. Cancer 1999;86:170-176. 